\title{
Policy Implementation: Teachers' Role as First Responders in Emergencies and Disasters
}

\author{
Shabbir Hyder ${ }^{1}$, Adnan Fazal Manzoor ${ }^{1 *}$, Muhammad Amjad Iqbal ${ }^{2}$
}

${ }^{1}$ Department of Management Sciences, COMSATS University Islamabad, Pakistan

2Deputy Director Response, National Disaster Management Authority (NDMA) Islamabad, Pakistan

\begin{abstract}
During the past decade, the schoolchildren faced many disasters and emergencies originating from natural and man-made sources. The safety of schoolchildren rests with school management and teachers. This study aimed to assess teachers' awareness with regard to disaster prevention and health, safety, security, and environment (HSSE) policies at primary schools in Pakistan. In addition, it explores the suitability of teachers to perform as emergency handlers in the absence of school nurses and resource officers (SROs). The study involved a qualitative study, based on open-ended interviews from a sample of 25 school teachers. Methodology triangulation was applied to reduce bias. Results revealed that the majority of teachers do not know about national policies related to school safety and security. Most of the teachers had been assigned additional roles as safety officers at the school, though they lack relevant training. Moreover, neither safety nor security aspects are incorporated into national educational policy. This study was the first study on Pakistani teachers' roles as emergency first responders. With the highest rate of attacks on educational institutions globally, the region still lacks a coherent policy structure. The study found numerous inconsistencies in public policies. It seeks to contribute to the literature to better understand the educational safety environment at both the ground and policy levels.
\end{abstract}

Keywords: educational policy, health, safety, security and environment (HSSE), school safety, teachers training, terrorism

\section{Introduction}

There has been a recent surge in terrorist attacks on educational institutions throughout the world, especially in Pakistan. The highest number of terrorist attacks on educational institutions in Pakistan were reported in 2010. ${ }^{1}$ These incidents have raised serious questions about schoolchildren safety. Safety at schools is a comprehensive term and includes aspects of physical, social, and emotional risk prevention and health education. ${ }^{2}$ The safety of students at schools can be shaken by violations of health, safety, security, and environment (HSSE) practices or by the impact of disasters, e.g., student safety at school can be jeopardized by disease (cholera, waterborne disease, parasitic infection, dehydration, influenza, hepatitis), or physical threats due to violations of safe practices, e.g., traffic injuries while en route to and from home ${ }^{3}$ physical assault, injuries while at play, bomb blasts, fire incidents, and sexual abuse. ${ }^{4}$ These incidents can quickly turn disastrous.

Disaster is defined as a severe disruption of the functioning of a society/community, involving extensive hu-

Correspondence*: Adnan Fazal Manzoor, Department of Management Sciences, COMSATS University Islamabad, Attock Campus, Kamra Road, Attock, Pakistan, Email: chemengg1980@gmail.com, Phone: +92-332562 4128 man, material, economic and/or environmental losses and impacts, which exceed the capacity of the affected society/community to cope using its own available resources. ${ }^{5}$ The criteria for disaster is 10 or more deaths and/or 100 or more people affected and/or declaration of a state of emergency/call for international assistance. ${ }^{6}$ On the contrary, the term occupational safety and health, also commonly referred to as occupational health or occupational health and safety, is a multidisciplinary field engaged with the welfare of working people. Although, HSSE laws are specifically made for workplace incidents, the same laws apply to schools, in as much as children are at least as prone to suffer harm or injury through an incident or accident. ${ }^{7}$

Implementation of HSSE and disaster prevention measures require specialized skills. For example, in the USA, the concept of appointing school resource officers (SROs) and school nurses is gaining popularity. School resource officers are specialized persons performing different roles such as law enforcers, consultants, and educators. Their role is widely discussed in the literature. ${ }^{8}$

Received : February 08, 2019

Accepted : February 10, 2020

Published: November 28, 2020 
However, in the event of SRO or school nurse absence, the teachers must carry out the additional jobs of managing health and safety. ${ }^{9}$ Many countries have models in which all teachers are required to be trained in emergency and disaster management. For example, in Armenia, military science teachers act as civil defense officers in school. Their skills include triage, first aid, and post-disaster psychological consultations. ${ }^{10}$ Previous studies have revealed that teachers have inadequate knowledge in the field of disaster management, ${ }^{11}$ first aid, ${ }^{12}$ and emergency response. Researchers have proposed such training for better school health systems. ${ }^{13}$

For successful safety policy implementation of newly issued policies, school administrators must involve teachers in the formulation of new plans. ${ }^{14}$ In the face of emergencies, the teachers' role has been defined as that of first responder. ${ }^{15}$ Trained teachers can handle emergencies effectively. ${ }^{16}$ In any situation, irrespective of impact and type of crisis, school teachers and relevant stakeholders act as first responders to access and notify the administration to activate emergency plans. They have to do this task for an extended duration of time as specialists when law enforcement agencies and health professionals, for example, are not readily available. ${ }^{15}$ Natural disasters like earthquakes and floods, ${ }^{17}$ have a long history of property as well as human damage. Natural disasters damage schools as well as students. In addition to natural disasters, the schools are also prone to manmade disasters, especially terrorist attacks. The most prominent of these was the incident at the Army Public School (APS) in Peshawar, Pakistan in 2014, where about 200 people including 184 children were brutally killed. The incident resulted in a paradigm shift in the country's educational safety program. ${ }^{18}$ Globally, Pakistan has suffered from the highest number of terrorist attacks on educational institutions. Details of the top terrorist attacks on schools worldwide, from 1970-2016 and 2010-2016, are shown in Table $1 .{ }^{19}$

As is evident from Table 1, during the period from 1970 to 2016, Pakistan suffered approximately 300\% more attacks on its educational institutions compared to the second country on the list, Thailand. However, if researchers look at the later 2010-2016 period, most of the attacks occurred during those years. Those comprised some $80 \%$ of the total attacks on educational institutions in Pakistan. Surge in these attacks clearly indicate the need for a reassessment of the existing policies.

Even beyond such disasters, the safety state at schools less than satisfactory. Important HSSE facets are almost neglected. Pakistan does not have a national survey explaining the level of HSSE. Therefore, authors are employing some anecdotal evidence to represent the sorry state of the schools HSSE affairs. Numerous incidents involving students, especially at the primary school level, have been recently reported. The violation of poor HSSE conditions may lead to serious incidents/accidents. For example, 734 female students fainted during the fumigation process in a primary school in Attock. ${ }^{20}$ The same incident was repeated in Jhelum, affecting more than one hundred school girls, ${ }^{21}$ while one hundred twenty students fainted from heatstroke in Dragai. ${ }^{22}$ In Lahore, nearly 40 students fainted due to toxic fumes at their school. ${ }^{23}$ Drinking water contamination has also been reported, as in Sukkur, where approximately 40 students were affected by diarrhea. ${ }^{24}$ These are some of the incidents indicating the lack of HSSE measures in the educational sector in Pakistan. As one can observe, the policies and measures came about mostly in response to external stimuli rather than a well-thought-out plan. Due to the various public stakeholders involved, there is no single policy document catering to HSSE and disaster aspects in educational institutions.

This lack of clarity clearly raises questions regarding the emergency response at schools. The teacher's role has been clearly indicated as that of first responder for emergencies. ${ }^{15}$ However, ambiguous formal policies also leave teacher roles somewhat ill-defined. Thus, they may not respond to situations as expected.

The objectives of this study are to determine whether teachers in primary schools are aware of national policies about child safety at school, whether they understand their roles as first responders in emergency situations, and to assess the HSSE/disaster prevention arrangements at their schools. More precisely, researchers ask the following questions, such as 'Do teachers have basic understanding and awareness about HSSE and disaster prevention measures as presented in various policies?', 'Do the schools have specialized officers and staff such as SRO and school nurses to manage emergencies and disasters?', and 'Do the teachers acquire role-specific training/education about HSSE and disaster prevention?'.

\section{Method}

The study design was qualitative and exploratory, as this topic has received scarce attention in the literature. To probe into existing problems and assessing the teachers in their additional roles, the study aimed to conduct

Table 1. Worldwide Highest Number of Attacks on Educational Institutions (1970-2016)

\begin{tabular}{lccc}
\hline \multirow{2}{*}{ Country } & \multicolumn{2}{c}{ Total Number of Attacks } & Proportion of Attacks (\%) \\
\cline { 2 - 4 } & (1970-2016) & (2010-2016) & (2010-2016) \\
\hline Pakistan & 944 & 737 & $78 \%$ \\
Thailand & 321 & 179 & $56 \%$ \\
Afghanistan & 326 & 204 & $63 \%$ \\
India & 301 & 186 & $62 \%$ \\
Iraq & 266 & 171 & $64 \%$ \\
\hline
\end{tabular}

Source: Global Terrorism Database ${ }^{19}$ 
exploratory research. The study sought to ascertain a new phenomenon-that of teachers working in secondary roles and asking questions about their new role. The data collection methods were open-ended, in-depth interviews, and analysis of policy documents (National Educational and Disaster Policy of Pakistan). Interview questions were initially developed by reviewing relevant literature. The instrument was reviewed for face and construct validity with by key informants selected by stratified sampling, comprising school principals (03), local experts (02), security officials (03), and school counselors (04) (teachers and community members). Face and construct validity was later found to be satisfactory during discussions with respondents. On the recommendation of key informants, the questionnaire was further modified. The final instrument contained 20 questions measuring teachers' awareness about HSSE and disaster prevention policies, teacher emergency education and training, and establishment of HSSE set up at schools, e.g., school safety statements and school hierarchy for implementing and monitoring HSSE and disaster management. The interview was used to conduct a thematic analysis. The methodology focuses on thematic analysis and was conducted in six steps. ${ }^{25}$ Teachers were approached through their respective school principals after obtaining approval. Document analysis of publicly available policy documents was a type of qualitative investigation where in content was interpreted to extract meaning by researcher. Methodology triangulation was done by combining the documentary evidence with themes generated from interviews to reduce bias and establish credibility. They were similar to focus groups or interviews incorporating coding content into themes. ${ }^{26}$ Total of 25 teachers from primary schools were interviewed through snowball sampling in the Attock District during the January-March 2018 time period. Twelve teachers were male and 13 were female; age ranged from 21 to 55 years. The area of study was chosen for its likely exposure to disasters, as Attock borders two provinces, e.g., Punjab and Khyber Pakhtunkhwa, which are prone to many natural and manmade disasters.

\section{Results}

According to the study objectives, the key result are presented. The essential data are displayed in the form of bar charts. Three broad themes emerged from the analysis.

Theme no. 1. Shallow Knowledge about Existing Policies

Results gathered show that, in general, teachers have a shallow knowledge of existing national policies related to the safety and security of children while at school. They do not know about educational and other policies and their HSSE content. As one respondent said, "I do not know that national educational policy contains the elements of safety and security and what is expected from us.". Teachers have been assigned the additional roles of safety/security officers in Pakistani schools, yet they know little about the existence of national educational policy and its content related to the safety of children. Approximately three-fourths of participants (76\%) showed a lack of knowledge. Moreover, it was observed that national educational policy does not cover the full spectrum of safety and security topics. As one respondent who happened to be aware of the education policy stated, "The national educational policy does contain quality standards for the school learning environment, but I do not think it contains disaster and security measures.".

To ascertain their awareness of disaster management, reaserchers asked participants what they knew about any disaster management policy. Most of respondents did not know of any disaster management policy. Out of the 25 participants who responded to the question, 24 reported that they did not even know of the existence of any disaster management policy.

Respondents also had little idea about security policy. Only 16\% indicated that they knew about national security policy. Those who were aware considered security to be the role and task of security and law enforcement agencies. As one respondent stated, "I think in our country, the security affairs are being looked after by army and police. They should know the national action policy or any other security policy.".

\section{Sub Theme. Fire-Fighting Approach}

Another observation to emerge from the data analysis was that teachers took reference and guidance from security advisories issued by local law enforcement agencies about the threat of terrorist attack. The same is the case with health-related advisories. Major respondents said that, with regard to safety issues, they received advisories from different government sectors (health agencies, police) via the education department. Results suggest that teachers are interpreting the local advisories as national-level policies. Out of 25 teachers, $60 \%$ knew

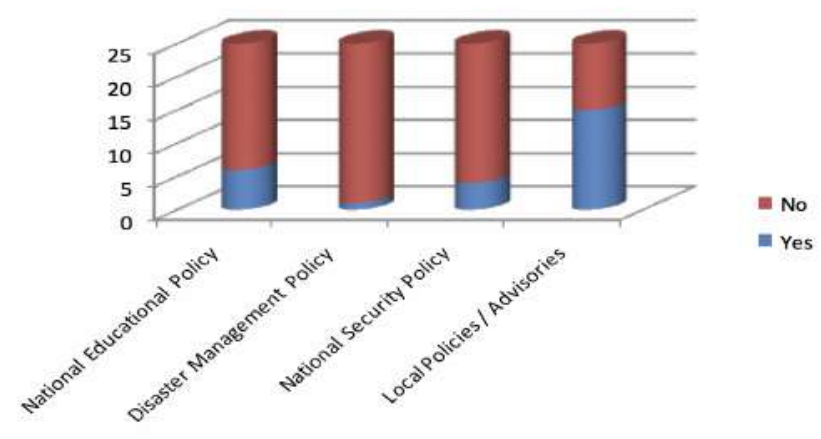

Figure 1. Awareness of Teachers about National Disaster Management Policies 
about local advisories/procedures. However, there appeared to be no single policy available that addressed all hazards. As one respondent stated, "I do not know about any single document that addresses all the potential hazards a school can face.".

The present educational policy does not address all hazards. It only discusses health and hygiene issues. Figure 1 presents the summary statistics of teacher awareness levels regarding different national and local policies in the form of a bar chart.

Theme no. 2. Non-Availability of Specialized School Staff

Results revealed that there is no plan for deployment of specialized staff-school nurses, welfare officers, SROs-at government schools in Pakistan. Of those interviewed, $100 \%$ indicated that there was no dedicated school nurse or SROs appointed in Pakistani schools. One respondent stated, "There is no specialized safety officer or school nurse available at our school. I think that there is no such position at schools.". The majority of responders stated that teachers have been assigned additional roles as safety/security and welfare officers. Result showed that 24 of $25(96 \%)$ teachers were performing those additional duties.

\section{Theme no. 3. No Specific Education/Training Roles}

Results indicated that teachers were performing additional duties without being educated or trained in the relevant discipline. Teachers were asked about their prior education backgrounds regarding health, safety, and security. Surprisingly, no teacher held relevant educational qualifications in HSSE or disaster management. The majority of respondents agreed that they had been assigned additional duties and the same number were endorsed by the directory of duties, but they had no background/education in these matters. A common view among interviewees was that they were not paid for the additional HSSE duties. Due to the non-availability of monetary benefits, they treated this duty as a burden for which they had no background education. Nor were they induced to perform safety/security duties. Similarly, no extensive rolespecific training was imparted to teachers to become first responders in emergency situations. They had been trained in specific disciplines on a need-basis only. As one respondent stated, "I was assigned the additional role of security officer after the incident at APS, and training was imparted to me at that time, but it was also only in the domain of security and no refresher training has been imparted since then.".

From the data in Figure 2, it is apparent that only $20 \%$ (five of 25) respondents indicated that they were trained in safety-related issues. The majority of respondents stated that they did not receive any occupational

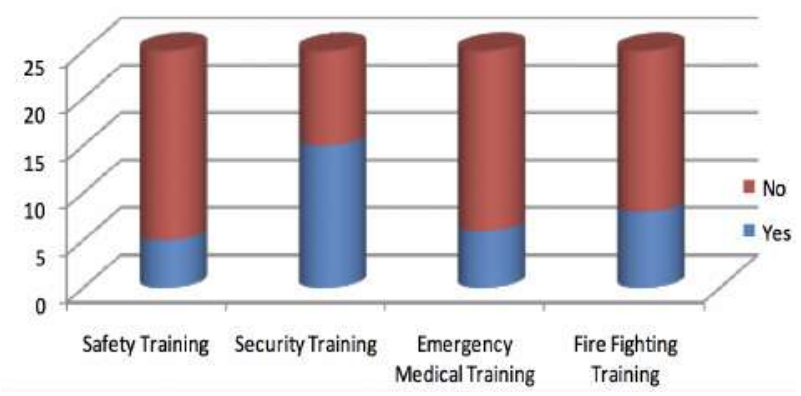

Figure 2. On-the-Job Training of Teachers Regarding Emergency Management

safety-related training. Fifteen of 25 participants $(60 \%)$ said that they were trained by local police in security disciplines. Similarly, six of $25(24 \%)$ teachers were given emergency health-related training. Only eight out of 18 teachers were taught fire-handling training. Results indicate that only security-related aspects specially related to acts of terrorism are being addressed at schools, due to the prevailing fragile security situation in the region. Results also revealed that there was no continuous process of training at the school level, as the majority of respondents mentioned that they received security-related training only after the APS incident in late 2014. Still, no training was provided after that on regular basis. The teachers were imparted on-the-job training after being assigning the tasks but found that training to be of little value. Only a small number of respondents indicated that they were now proficient to handle emergencies situations. As one respondent stated, "I think that I can handle an emergency but I am not sure about it.".

Together these results provide important insights about the state of teacher awareness and preparedness against disasters and accidents. Overall, the results indicate that teachers have only a very superficial knowledge of national-level policies dealing with safety, security, and disaster prevention at schools. Teachers are performing the additional duties of safety and security without proper education and relevant training. In addition to poor awareness levels, it was learned that there is no proper HSSE setup and disaster prevention at schools. Safety, security, and health-related tasks are being accomplished in piecemeal.

\section{Discussion}

The primary goal of this study was to ascertain the awareness level of primary school teachers about school safety. School safety needs specific attention from school management, parents, and relevant stakeholders. ${ }^{27}$ In South Asia, especially in Pakistan, there have been many incidents affecting school safety. ${ }^{18}$ This paper also reviewed various policies about school safety and security. 
Results indicate that, although teachers have been assigned the additional roles of safety/security officers, ${ }^{9}$ they still lack basic training. In developed nations, school nurses and SROs are deployed to handle emergency situations. However, in many under-developed countries, specialists are not available at school and teachers have to execute these duties themselves. This finding was also supported by previous study in which school headmasters were made responsible for the safety and security of elementary schools. ${ }^{28}$

Secondly, teachers are only poorly aware of national policies about school safety and security. The majority of teachers were unaware of different government departments responsible for safety and disaster management. Nor did they have any idea about national safety and disaster policies. What is surprising is that teachers refer to local advisories as national-level policies. School safety is a comprehensive discipline. Therefore, teachers must be aware of basic safety knowledge to cope with any emergency situation.

The third major finding was that teachers never received safety and security courses in their curricula before becoming teachers. While after the terrorist incident of APS, teachers were provided basic emergency response classes and even small weapons training. That training was primarily conducted for security purposes, while safety, health, and environmental aspects were missing. Besides, the impact of the training died down over time, since no refresher courses were made available. The findings further reveal that teachers have little knowledge of risk assessment procedures at schools.

A possible explanation may lie in the fact that most safety and security duties are not included in their job descriptions. They were assigned additional duties as safety and security officers with very little preparation. ${ }^{9}$ Moreover, they consider this duty as an additional burden without any monetary benefit. These teachers are not made aware of national safety, security, and disaster prevention policies. Furthermore, teachers' roles as first responders are still not fully defined in national educational policy. ${ }^{29}$ They are hired based on their educational backgrounds with almost no emphasis on safety. Add to that, continuous teacher training programs are difficult to arrange because of lack of resources for schools. ${ }^{30}$ These problems certainly require reconsideration and change in relevant public policies.

Finally, a number of important limitations need to be considered. The study is a qualitative investigation, which has its own demerits. A mixed-method approach may more fully reveal the overall safety setup at schools. This study was conducted in Attock, a small Pakistani city. Similar studies in different South Asian countries may give us a better picture of school safety needs.

\section{Conclusion}

The study was conducted to determine the awareness level of primary school teachers about school safety policies. As safety is a primary responsibility of school management and teachers, teachers should be prepared as per their roles and tasks. This study has shown that teachers are generally unaware about the existence of school safety policies. Moreover, teachers are unaware about the different national institutions responsible for safety and disaster prevention at schools. The evidence from this study suggests that the awareness level of teachers about existing national safety/disaster policies needs to be upgraded.

\section{Recommendation}

The findings of this study suggest a number of important implications, including revision of national educational policy by integrating it with other safety and disaster management policies, in order to yield a single comprehensive document and and induction of specialized staff, e.g., a school nurse and SROs. Teachers should be declared first responder in national educational policy by defining and establishing their roles in an emergency. Teachers should be given appropriate training about emergency management. To motivate them to carry out the additional tasks, special incentives and monetary benefits should be accorded them. This research will serve as a basis for future studies about teachers' roles as first responders in educational settings where SROs/school nurses are not available. Moreover, future studies may also consider the competency levels of teachers as first responder. This study will help policy makers rationalize existing programs.

\begin{abstract}
Abbreviations
HSSE: Health, Safety, Security, and Environment; SRO: School Nurses and Resource Officers; APS: the Army Public School.
\end{abstract}

\section{Ethics Approval and Consent to Participate}

Obtain

\section{Competing Interest}

Author declares that there are no significant competing financial, professional, or personal interests that might have affected the performance or presentation of the work described in this manuscript.

\section{Availability of Data and Materials}

The authors have access to all the data in the study and take responsibility for the integrity of the data.

\section{Authors' Contribution}

Shabir Hyder, Adnan Fazal Manzoor, and Muhammad Amjad Iqbal participated in the planning, analysing data, drafting, and reviewing the article drafts. 


\section{Acknowledgment}

Not Applicable

\section{References}

1. LaFree G, Dugan L, Miller E. Putting terrorism in context: lessons from the global terrorism database. Routledge; 2014.

2. Díaz-Vicario A, Gairín SJ. A comprehensive approach to managing school safety: case studies in Catalonia, Spain. Educational Research. 2017; 59 (1): 89-106.

3. Şimşekoğlu Ö, Nordfjærn T, Rundmo T. Traffic risk perception, road safety attitudes, and behaviors among road users: a comparison of Turkey and Norway. Journal of Risk Research. 2012; 15 (7): 787-800.

4. De Venanzi A. School shootings in the USA: popular culture as risk, teen marginality, and violence against peers. Crime, Media, Culture. 2012; 8 (3): 261-78.

5. United Nations Office for Disaster Risk Reduction. 2009 UNISDR terminology on disaster risk reduction. Geneva, Switzerland; 2009.

6. Guha-Sapir D, Vos F, Below R, Ponserre S. Annual disaster statistical review 2010. Centre for Research on the Epidemiology of Disasters. 2011.

7. Lane J. Health and safety law update school safety: separating myths from reality. CILEx Journal. 2017; 7 (2017)

8. Chrusciel MM, Wolfe S, Hansen JA, Rojek JJ, Kaminski R. Law enforcement executive and principal perspectives on school safety measures: school resource officers and armed school employees. Policing: An International Journal of Police Strategies \& Management. 2015; 38 (1): 24-39.

9. Shiwaku K. Comparative study on teacher training for school disaster management in Armenia and Japan. Disaster Prevention and Management. 2014; 23 (2): 197-211.

10. Chong KM, Mahama $\mathrm{H}$. The impact of interactive and diagnostic uses of budgets on team effectiveness. Management Accounting Research. 2014; 25 (3): 206-22.

11. Joshi SG, Sawane K, Jabade M. Effectiveness of training manual on disaster management in terms of knowledge and self-expressed practices among secondary school teachers in selected schools of Pune City. International Journal of Science and Research (IJSR). 2015; 4 (9): 2093-6.

12. Li F, Jiang F, Jin X, Qiu Y, Shen X. Pediatric first aid knowledge and attitudes among staff in the preschools of Shanghai, China. BMC Pediatrics. 2012; 12 (1): 121.

13. Mersal FA, Aly RA-ES. Developing disaster management and first aid guidelines for school teachers in Cairo Egypt. Journal of Nursing Education and Practice. 2016; 6 (7): 41.

14. Martin LE, Kragler S, Frazier D. Professional development and educa- tional policy: a comparison of two fields in education. Journal of Educational Research and Practice. 2017; 7 (1): 60-73.

15. Kingshott BF, McKenzie DG. Developing crisis management protocols in the context of school safety. Journal of Applied Security Research. 2013; 8 (2): 222-45.

16. Adiyoso W, Kanegae H. The effect of different disaster education programs on tsunami preparedness among schoolchildren in Aceh, Indonesia. Disaster Mitigation of Cultural Heritage and Historic Cities. 2012; 6 (July): 165-72.

17. Tariq MAUR, Van de Giesen N. Floods and flood management in Pakistan. Physics and Chemistry of the Earth, Parts A/B/C. 2012; $47-$ 48: 11-20.

18. Qayyum S. A study of intentions of terrorist attack on APS School Peshawar, reactions and panacea by government; 2015.

19. National Consortium for the Study of Terrorism and Responses to Terrorism (START); 2017.

20. Digital S. Over 700 girls pass out after dengue spray 10 September 2015; 2015.

21. Correspondent. Spurious dengue spray: after attock after attock, 105 students in Jhelum school faint. The Express Tribune, September 13th, 2015; 2015.

22. Khan GA. Students faint to heat stress at Dragai School. Dawn; 2016.

23. The Newspaper's Staff Reporter. Fainting: CDGL team blames school owner. Dawn; February 23, 2015.

24. Editorial. Waterborne diseases. The Express Tribune; 2013.

25. Maguire M, Delahunt B. Doing a thematic analysis: a practical, stepby-step guide for learning and teaching scholars. AISHE-J: The All Ireland Journal of Teaching and Learning in Higher Education. 2017; 9 (3): 3351-14

26. Mohajan HK. Qualitative research methodology in social sciences and related subjects. Journal of Economic Development, Environment and People. 2018; 7 (1): 23-48.

27. Robers S, Kemp J, Rathbun A, Morgan RE. Indicators of school crime and safety: 2013. National Center for Education Statistics, U.S. Department of Education, and Bureau of Justice Statistics, Office of Justice Programs, U.S. Department of Justice. Washington, DC; 2014.

28. Rahardjo S. The effect of competence, leadership and work environment towards motivation and its impact on the performance of teacher of elementary school in Surakarta City, Central Java, Indonesia. International Journal of Advanced Research in Management and Social Sciences. 2014; 3 (6): 59-74.

29. Government of Pakistan. Educational policy standards for school learning environment. In: ministry of Education, editor; 2017-2018

30. DeAngelis KJ, Brent BO. Books or guards? Charter school security costs. Journal of School Choice. 2012; 6 (3): 365-410. 